\title{
A VISITA DOMICILIÁRIA COMO INSTRUMENTO DE ASSISTÊNCIA DE SAÚDE*
}

HOME VISIT AS A MEANS GOR HEALTH ASSISTANCE

Márcia Maria Porto Rossetto Mazza ${ }^{1}$

MAZA, M. M. P. R. A Visita Domiciliaria como Instrumento de Assist8ncia de Sable. IRev. piras. Crese. Dás. Hum., São Paulo, IV(2), 1994.

Resumo: O presente trabalho pretende propiciar uma reflexão sobre as razões aparentes do desuso da visita domiciliária no contexto da Saúde Pública. Para isto, buscou-se identificar bibliografias que permitissem vislumbrar a situação atual da visita domiciliária, destacando-se o contexto familiar em que ela se desenvolveu. Procurou-se caracterizar seu processo histórico no mundo, destacando-o no Brasil, focalizando suas ligações com o surgimento da Enfermagem.

Palavras-chave: visita domiciliária, histórico, instrumento de saúde, promoção de saúde, educação em saúde.

Summary: The present study intends to pose a reflection about lhe apparent reasons of lhe disuse of lhe home visit in lhe Public Health context. To do so, lhe author tried to identify bibliografias that provided a notion of lhe current situation of home visit, pointing out lhe family context in which it developed. The study also describes the historical process of this practice in the world, with special attention to Brazil, and its relation with the arising of Nursing in this country.

Key-words: home visit, account, health rneans, health promotion, health education.

* Este trabalho faz parte de um estudo monográfico realizado como exigencia da disciplina Temas Avançados em Sadde Cole iva do Programa de Pós-Graduação em Enfermagem Saúde-Coletiva - nível mestrado da Faculdade de Enfermagem/USP, cursado pela autora como aluna especial em junho de 1994.

1 Enfermeira, Pesquisadora do Centro de Estudos do Crescimento e do Desenvolvimento do Ser Humano, Faculdade de Saúde Pública/USR.

End.: Av. Dr. Arnaldo 715, subsolo sala 21, São Paulo - SP, CEP 01246-904 Fone/Fax: (011) 851.3572 


\section{INTRODUÇÃO}

Este trabalho visa propiciar uma reflexão sobre a visita domiciliária como um dos instrumentos de prestação de assistência à saúde.

Empiricamente, percebemos que, com o passar do tempo, essa atividade foi desaparecendo dos serviços, e o que pode ser verificado atualmente é que a mesma está sendo realizada apenas esporadicamente e somente em raros serviços de saúde.

O tema merece reflexão, pois, a visita domiciliária é um dos instrumentos mais indicados para se começar a trabalhar o indivíduo, a família e a comunidade na prestação de assistência à sua saúde, dentro do seu contexto social, desde que seja realizada mediante processo racional e com objetivos definidos que estejam dentro dos princípios de eficiência.

Considerando a perplexidade que o desuso da visita domiciliária nos causa, optamos pela realização de um trabalho em que buscássemos esclarecer, ou pelo menos, levantar hipóteses, sobre as razões de tal desuso.

Para delimitar o problema, procuramos, por meio de pesquisa bibliográfica, levantar informações que pudessem nos situar sobre a real importância da visita domiciliária, considerando manifestações de autores de renome que a preconizem e a conceituem.

O texto da Constituição Brasileira, regulamentado pela Revisão Constitucional de 1988, apresenta uma seção relevante sobre a saúde em que distingue três aspectos principais:

$1^{0}$ aborda um conceito mais amplo, em que a saúde tem como fatores determinantes e condicionantes o meio físico no qual se incluem algumas de suas características específicas: condições geográficas, água, alimentação, habitação, etc.; o meio sócio-econômico e cultural: ocupação, renda, educação, etc.; fatores biológicos: idade, sexo, fatores genéticos, etc.; e a "oportunidade de acesso aos serviços que visem à promoção, proteção e recuperação da saúde";

$2^{0}$ legitima "o direito de todos, sem qualquer discrirninação, às ações de saúde”, em todos os níveis, assim como explícita que o “dever de prover o pleno gozo desse direito é responsabilidade do governo".

$3^{\circ}$ estabelece O Sistema Unico de Saúde - SUS - de caráter público, formado por uma "rede de serviços regionalizados, hierarquizados e descentralizados, com direção única em cada nível de governo e sob controle dos seus usuários” (MINISTERIO DA AUDE, 1990).
A Lei, que define o Sistema Unico de Saúde, coloca que as atividades de assistência à saúde devem ser regidas pelos princípios doutrinários de "universalidade", “eqüidade” e "integralidade”.

Estes princípios só serão assegurados se obedecerem à organização do Sistema Unico de Saúde, que, além da regionalização e hierarquização, visam também à resolubilidade, descentralização, participação dos cidadãos e complementariedade do Setor Privado.

Por outro lado, o texto da Conferência de Alma Ata no qual são explicitados preceitos para os cuidados primários em saúde, permite que se possa considerar a atenção domiciliária como um dos meios de se obter do indivíduo, da família e da comunidade sua participação no planejamento, organização, operação e controle desses cuidados fazendo uso dos recursos locais disponíveis.

Com a finalidade de mobilizar a comunidade e conseguir seu envolvimento, um dos recursos que pode ser utilizado é o processo de educação em saúde, por meio de visita domiciliária (CONFERENCIA INTERNACIONAL SOBRE CUIDADOS PRIMÁRIOS DE SAUDE, 1979).

Tais ponderações foram incorporadas na estrutura do SUS, no Brasil, na medida em que nele é estabelecido que "para melhor identificar quais os principais grupos de ações de promoção, proteção e de recuperação de saúde a serem desenvolvidos prioritariamente, é necessário ‘conhecer’ as principais características do perfil epidemiológico da população, não só em termos de doenças mais frequentes, como também em termos das condições sócio-econômicas da comunidade: hábitos, estilos de vida e suas necessidades de saúde sentidas e/ou não-sentidas, aí incluída, por extensão, a infra-estrutura de serviços disponíveis”(MINISTÉRIO DA SAUDE, 1990).

Partindo desses pressupostos e preceitos, pretendemos problematizar no período anterior e subsequente à implantação do SUS a estratégia assistencial de abordagem comunitária e familiar, por meio da visita dorniciliária- enquanto atividade institucionalizada - pois que, esta, ao longo do crescente desmantelamento dos serviços de saúde, vem caindo em desuso. As razões deste desuso não estão adequadamente caracterizadas, e, no nosso entender, merece maior atenção.

\section{CONCEITUAÇAO E FUNDAMENTAÇÃO TEORICA DA VISITA DOMICILIARIA}

A visita domiciliária constitui uma atividade de assistência à saúde exercida junto ao indivíduo, à família e à comunidade. Seu objetivo é contribuir para a efetivação das premissas de promoção de saúde definidas pela 
Organização Mundial de Saúde, e adoradas também, pelo Sistema Unico de Saúde no Brasil.

Esta atividade foi preconizada por renomados profissionais da área de enfermagem, pelos quais é indicada e reconhecida como estratégia para o trabalho na comunidade, sendo um método eficaz, pois pode despertar na população a preocupação para as questões de sua saúde, orientá-la na articulação com outros serviços para a resolução de seus problemas e fornecer-lhe subsídios educativos para torná-la independente.

Segundo COSTA (1977), “a visita domiciliária como atividade dirigida à família enseja um tipo de ensino voltado à solução de problemas de vivência em situações da vida real, no ambiente familiar".

É uma atividade caracterizada fundamentalmente pela interação entre indivíduos, e aí, a comunicação assume uma importância decisiva.

Segundo ARCHER \& FLESHMAN (1977), “a capacidade para comunicar-se é a habilidade de trocar pensamentos e mensagens com outra pessoa. Em uma entrevista o cliente e a enfermeira estão tratando de trocar idéias e a efetividade do intercâmbio depende da percepção que cada um tem do outro".

Para COSTA(1977), “a visita domiciliária se fundamenta no princípio de que todas as atividades de enfermagem junto à fami1ia têm o objetivo eminentemente educativo, e como um processo educativo, ela tem a finalidade de auxiliar a fami1ia a ajudar-se a si mesma”.

Segundo NOGUEIRA \& SERPADAFONSECA (1977), “a visita domiciliária é um método dos mais eficientes, utilizados pela Enfermagem há muito tempo, para proporcionar assistência à saúde da família”.

Os objetivos dessa atividade podem ser sintetizados conforme descrito por estas autoras:

- prestação de cuidados de enfermagem no domicílio quando for conveniente para o paciente, para a fami1ia e para o serviço de saúde sob o aspecto económico, social ou psicológico;

- orientação e educação a um ou mais membros da família para a prestação de cuidados no domicílio; - supervisão dos cuidados delegados à fami1ia;

- orientações à família em assuntos de higiene em geral, quando o ambiente do serviço de saúde não for o mais indicado, pois as condições não serão as mesmas;

- coleta de informações sobre as condições sócio-sanitárias da família, por meio de entrevista e observação.

Com esses objetivos a visita domiciliária possui algumas vantagens e também limitações que merecem destaque.
Para
CA (1977):

Para NOGUEIRA \& SERPA DA FONSE-

São vantagens:

- proporcionar aos profissionais o conhecimento sobre o indivíduo, o seu verdadeiro contexto de vida ou meio ambiente, caracterizado pelas condições de habitação, pelas relações afetivo-sociais entre os vários membros da fami1ia, fatores importantes a serem identificados para a prestação da assistência integral à saúde;

- facilitar a adaptação do planejamento da assistência de enfermagem de acordo com os recursos de que a fami1ia dispõe;

- proporcionar melhor relacionamento do profissional com a familia, por ser um método menos formal e mais sigiloso em relação aos utilizados em outras atividades dos serviços de saúde;

- proporcionar maior liberdade para os clientes ou pacientes exporem seus problemas, pois o tempo dedicado a eles é bem maior.

São limitações:

- é um método relativamente caro, comparado com outros, pois depende da utilização de pessoal treinado e, muitas vezes requer transporte; - pequeno rendimento em relação a outros métodos, pois é gasto muito tempo não só na execução da visita, como também na locomoção do profissional e, posteriormente, na avaliação da visita domiciliária;

- os afazeres da dona de casa ou mesmo a sua ausência por trabalhar fora, podem impedir ou dificultar a prestação deste tipo de assistência.

\section{RAÍZES HISTÓRICAS DA VISITA DOMICILIÁRIA}

Tradicionalmente, a visita domiciliária tem sido considerada uma importante atividade de enfermagem de Saúde Pública e o texto de AUGUSTO \& FRANCO (1980) permite identificar alguns períodos na sua evolução que, na verdade, está intimamente ligada à da própria enfermagem.

\section{Primórdios da visita domiciliária}

Segundo os autores citados, a assistência de Enfermagem Domiciliária data do período pré-cristão. Podemos dividi-la em dois períodos distintos que foram denominados de pré-científico ou religioso e o científico. 
No período pré-científico ou religioso, a visita domiciliária possuia um enfoque assistencialista, caracterizado pela "caridade", pois prestar serviços aos pobres e doentes era considerado como um serviço prestado a Deus, sem a preocupação com nenhum método que desse suporte científico aos trabalhos assistenciais prestados no domicilio.

Era realizada por várias ordens religiosas existentes. Os hebreus, em seu código civil, já preconizavam o atendimento e o cuidado ao pobre, aos desprovidos, aos doentes e à mulher no período puerperal, em seu domicilio, por pessoa provida de conhecimentos.

Na Era Cristã, os Apóstolos, referindo-se aos ensinamentos de Cristo relatados na Bíblia, exaltavam esse atendimento aos mais necessitados. Lucas, em uma passagem bíblica, afirma: "Estava doente e me visitaste".

Num segundo período, por volta de 1500, ainda sob grande influência religiosa, a assistência domiciliária assume um caráter mais metódico.

No Século XVI, São reticente de Paula cria, na Itália, o Instituto das Filhas de Caridade em que as irmãs prestavam assistência aos doentes e aos pobres em seu domicilio. Para esse atendimento, foi preconizado um manual no qual se detalhavam todos os procedimentos e etapas que deveriam ser seguidas. Esse manual continha uma parte especifica sobre a visita domiciliária denominada "A Procura de Doentes".

O inicio do chamado período científico foi marcado por uma sistematização dos procedimentos da visita dorniciliária ocorrido por volta de 1850.

Esse processo passa a ser cada vez mais elaborado, difundindo-se simultaneamente na Europa e nos Estados Unidos.

AUGUSTO \& FRANCO (1980) relatam que "nessa ocasião, illiarn Rathbone achava que para executar tal tarefa a mulher precisava ser educada e treinada".

Diz também que, a partir dessas ideias, foi criado na cidade de Liverpool - Inglaterra um serviço de Enfermagem Distrital, que teve grande repercussão e espalhou-se por todo país.

\section{O inicio da capacitação profissional}

Para que a visita domiciliária atinja seus objetivos outro fator importante deve ser considerado em relação, ao tipo de profissional que a executará. Esse profissional deverá estar bem preparado tecnicamente, quanto ao conhecimento de quem será visitado, local a ser visitado e objetivos da visita. Deverá ser cordial, criativo, gostar do que faz, manter uma neutralidade que não prejudique sua interação com a família.
O período que marca, no nível regional, (Inglaterra), a regulamentação para a capacitação profissional tem seu inicio em 1909, quando o Conselho Municipal de Londres disciplina e regulamenta a formação das visitadoras (AUGUSTO \& FRANCO, 1980).

Nos Estados Unidos, mais especificamente em Nova York, a visita domiciliária teve inicio aproximadamente em 1900, sendo criada a instituição "Visiting Nurses Association", que logo se estendeu para outros estados do pais (AUGUSTO \& FRANCO, 1980).

Em 1902, Lina Rogers cria a primeira escola de serviço especializado que também logo se expandiu por todo 0 país.

As enfermeiras visitadoras formadas nesta escola dedicavam-se ao trabalho com o grupo materno-infantil e com pacientes acometidos de tuberculose. Posteriormente, a visita domiciliária foi ampliada, passando a incorporar todo tipo de serviço de enfermagem que o paciente precisasse em domicilio, situação esta que se manteve até décadas recentes.

\section{Inicio da enfermagem no Brasil}

De acordo com MIRANDA (1987) em sua dissertação de mestrado, pode-se verificar que, do Século XV1 até o Século XVIII, as doenças que acometiam a população brasileira recebiam atendimento através do Físico-Mor e do CirurgiãoMor, modelo médico português, que não tinha nenhuma relação com a higiene pública.

A Fisicatura, Pronto-Medicato e posteriormente as Ordenações Filipinas foram as entidades que prestavam assistência à saúde da população.

Os médicos portugueses, então subordinados à administração colonial, de quem recebiam salários e obrigações especificas, não aceitaram vir para o Brasil, pois, as dificuldades eram muito grandes, tais como desconhecimento da flora local, distanciamento dos remédios europeus e poucas vantagens profissionais.

As formas alternativas de tratamento e cura eram baseadas nos conhecimentos dos indígenas, dos negros, dos jesuítas e dos próprios fazendeiros.

Segundo MIRANDA (1987), "podemos começar a considerar o nascimento da enfermagem no Brasil, com a fundação por José de Anchieta, da Santa Casa de Misericórdia do Rio de Janeiro". O cuidado hospitalar aos doentes era desenvolvido por voluntários leigos, religiosos e pelos escravos, tendo os médicos um papel secundário, sendo que esse atendimento era direcionado aos pobres, forasteiros, soldados, marinheiros e loucos. 
Esse período foi o equivalente nacional ao período religioso europeu.

Com o passar do tempo as Casas de Misericórdia começam a apresentar incapacidade de assistir até esses doentes, em particular os soldados feridos, e a ameaçar os interesses financeiros e militares da coroa.

No entanto, no Brasil, somente quarenta anos depois do início do chamado período científico na Europa e nos Estados Unidos, é que se começa a tomar as primeiras providências para sistematização do preparo de pessoa', para o cuidado com o doente. Os hospitais, que até então eram dirigidos pelos religiosos, passam para o controle direto do governo.

No Rio de Janeiro é criada a escola Profissional de Enfermeiras, sob influência do pensamento francês. O objetivo deste curso era preparar enfermeiras para prestar atendimento basicamente hospitalar e trabalhar em hospícios e hospitais civis e militares.

A atenção à saúde da população era basicamente de nível secundário e terciário, com ênfase, pois, predominantemente hospitalar.

Na década de 20 deste século, o Brasil começa a apresentar graves problemas de epidemias, entre elas cólera, tifo, varíola, febre tifóide e outras doenças contagiosas.

Foi necessário, então, repensar a saúde, preconizando-se à assistência de Saúde Pública como único meio de controlar e combater os males que aterrorizavam tanto a população carente, como aquela das classes dominantes do País. O Brasil perdia divisas para outros países, e sua economia, que era principalmente de exportação de produtos agrícolas, começava a sofrer represálias externas.

Em relação ao controle da saúde, o Brasil importava, então, dos Estados Unidos, o modelo médico sanitário que tinha como pressupostos a valorização das ações e medidas sobre o meio ambiente externo, como foco de doenças. $\mathrm{O}$ enfoque passa, então, dessa consideração para a do indivíduo como, também, envolvido no processo saúde/doença. Este modelo exerceu influência significativa na organização dos serviços de saúde pública brasileiros (OSHIRO, 1988).

“As medidas sanitárias têm um caráter autoritário e coercitivo e se traduzem nas campanhas sanitárias e polícia sanitária voltadas, basicamente, para os grupos sociais urbanos ligados ou não ao processo de produção” (OSHIRO, 1988).

Segundo essas notícias “O Estado, respaldado pelas práticas sanitárias científicas, penetra em todos os espaços sociais - fábricas, habitações, escolas impondo medidas higiénicas, onde as condições de salubridade existentes pudessem constituir entraves e ameaças ao desenvolvimento da produção”.
O texto não se refere explicitamente à visita domi ciliária, mas pode-se presumir que, em existindo essa tenha se prestado às mesmas finalidades.

\section{A visita domiciliária no contexto da enfermagem de saúde pública no Brasil}

O nascimento da visita domiciliária institucionali zada no Brasil tem seu marco inicial em artigo publicad< em 15.10.1919 pelo “O Jornal”, onde o Dr. J. P. Fontell aborda a educação sanitária e a necessidade de formação de enfermeiras visitadoras, sugerindo a criação desse serviço. O aparecimento do serviço de enfermeiras visi tadoras no Brasil é marcado com o objetivo de prevenção conforme afirma AUGUSTO \& FRANCO (1980).

Em 1920, Amaury de Medeiros introduz na EscoL de Enfermagem da Cruz Vermelha um curso de visitado ras sanitárias.

Neste mesmo ano foi criado o serviço de visita doras como parte do Serviço de Profilaxia da Tuberculo se. Tal iniciativa marca a inclusão da visita domiciliária como atividade de Saúde Pública, uma vez que o ser viço referido fazia parte do Departamento Nacional dá Saúde Pública, órgão pertencente ao Ministério da Jus tiça e Negócios Interiores, criado por decreto-lei dá 02.01.1920.

Em 1921, a pedido de Carlos Chagas, então direto do Departamento Nacional de Saúde Pública, sob o pa trocínio e cooperação do Serviço Internacional de Saúde da Fundação Roc^Kfeller, chegou ao Rio de Janeiro un grupo de enfermeiras visitadoras americanas. Estas de veriam orientar o processo de assistência a paciente tuberculosos tratados nos dispensários e também estuda a situação e elaborar propostas e sugestões para a forma ção de enfermeiras no Brasil.

Em 1922 foi criada a Escola de Enfermagem Anã Nery como instituição pertencente à Universidade do Ri de Janeiro. A enfermagem brasileira e em particular Escola de Enfermagem Anna Nery importaram o modela de enfermagem moderna de Florence Nightingale (MI RANDA, 1987).

Esta escola foi considerada a escola modelo dá Brasil. Seu objetivo maior era a formação de enfermeira com caráter de assistência predominantemente primária

As primeiras alunas diplomadas pela Escola dá En ferrnagem A nna Nery foram contratad as pe lo Dep ar lamento Nacional de Saúde Publica, cuja programação enfatizava 0 setor de profilaxia da tuberculose e saúde d; criança, com atenção especial à visitação domiciliária. 
As visitadoras deveriam, aí, prestar assistência, priorizando aspectos educativos de higiene dirigidos àquelas doenças (AUGUSTO \& FRANCO, 1980).

Paralelamente, em São Paulo, aproximadamente em 1926, foi criado o curso de educadoras sanitárias.

Em 1946, ingressaram na Faculdade de Saúde Pública (antiga Faculdade de Higiene e Saúde Pública) seis enfermeiras egressas da Escola de Enfermagem da Universidade de São Paulo, pertencentes à primeira turma de enfermeiras formadas por essa escola. Constituíram, juntamente com dez educadoras formadas pela Faculdade de Saúde Pública/USP, o grupo de visitadoras cuja função era a prestação de assistência domiciliária à saúde de pessoas residentes na área programática do Centro de Saúde Geraldo de Paula Souza, isto é: gestantes, crianças e portadores de doenças transmissíveis. Este trabalho perdurou até 1963, aproximadamente, quando o Centro de Saúde foi praticamente desativado, tendo sido abolido o serviço de visitação domiciliária sistemática².

Concomitantemente em todo o país, nesse período, foram sendo criados os dispensários e centros de saúde, os quais tinham como objetivo o tratamento da tuberculose, hanseníase, tracoma e a diminuição da mortalidade infantil. Dentro desses programas a visita domiciliária restringia-se apenas ao doente.

Em 1942 foi criada a Fundação SESP que objetivava promover o saneamento de áreas afetadas por agentes da febre amarela, malária e filariose, nas regiões Amazônica e Vale do Rio Doce, atendendo a esforço de guerra, para extração de matéria-prima necessária à fabricação de instrumental bélico. Concomitantemente, prestava assistência à saúde da população que se deslocava para a Amazônia a fim de explorar a borracha. Sendo os resultados da proposta eficientes, estes foram expandidos para os estados do Norte, Nordeste e Centro Sul, principalmente região do Vale do Rio Doce, por onde se escoava o minério de ferro a ser embarcado no estado do Espírito Santo.

Nesta assistência desempenhavam papel preponderante as visitas domiciliárias executadas por pessoal de nível médio, preparado pela própria Fundação como visitadoras sanitárias. Sua função era prestar assistência interna no Centro de Saúde e, externa, nos domicílios, a gestantes/ mães, crianças e doentes de moléstias contagiosas sob supervisão de enfermeiras ${ }^{3}$.

Em 1947 foi criado o Serviço Especial de Saúde de Araraquara (SESA), que tinha como pressupostos prestar assistência à população através da assistência de enfermagem domiciliária e servir de campo de estágio às enfermeiras e médicos do Estado de São Paulo e de outros estados (AUGUSTO \& FRANCO, 1980).

A assistência de enfermagem domiciliária era caracterizada por uma sistematização mais ampla, pois, além de seguir as orientações da época de São Vicente de Paula, preocupava-se também com a sistematização do processo de visitação: com o preparo anterior à realização da visita; uso de técnicas adequadas desenvolvidas no domicílio; de roteiro para realização da visita; estabelecimento de prioridade para os doentes portadores de doenças transmissíveis, que deveriam ser visitados separadamente ou em último lugar, para evitar infecções cruzadas; tendo preocupação com o tempo dispensado em cada visita (AUGUSTO \& FRANCO, 1980).

Pode-se depreender do breve histórico apresentado, que a visita domiciliária, predominantemente estratégia preventiva, pode ser entendida como a precursora das escolas de enfermagem no Brasil, situação esta que sofreria profunda transformação para um caráter principalmente curativo, em função da regulamentação da profissão do enfermeiro efetivada posteriormente.

Quanto ao posicionamento da visita domiciliária no contexto da Enfermagem de Saúde Pública, já na época dos "primórdios da visita domiciliária”, dentro das funções da Enfermeira de Saúde Pública, a visita domiciliária constituir-se-ia em um dos instrumentos mais eficientes para se trabalhar com a comunidade e com as famílias na promoção e na detecção de suas necessidades de saúde.

Como diz NOGUEIRA (1977), "são funções da enfermagem de saúde pública, com relação à família, aquelas que visam assisti-la no desempenho de atividades que contribuam para promover, proteger e recuperar a saúde de seus membros", operacionalizando, assim, a definição da OMS (1977): “entre as funções da enfermeira na assistência primária de saúde está a de capacitar indivíduos, famílias e comunidades a identificar, satisfazer e avaliar suas necessidades específicas de saúde, além de capacitar grupos da medicina tradicional e voluntários para participar dos programas comunitárias de saúde”.

Em reforço a essa tese, para finalizar, citamos Nogueira, adaptado de HORTA(1984), que diz "cabe à enfermagem comunitária, de comunidade ou de saúde pública, assistir ao ser humano, dentro da família e da comunidade, direta ou indiretamente, através da enfermeira e de pessoal auxiliar, para atender às necessidades humanas básicas e intervir na história natural da enfermidade em todos os níveis de prevenção”.

\footnotetext{
2 Relato verbal de enfermeiras contemporâneas à época citada, testemunhas pessoais de alguns destes fatos.
}

3 Relato verbal de enfermeira testemunha pessoal destes fatos, à época citada. 


\section{CONSIDERAÇÕES FINAIS}

Ao refletirrnos sobre a visita domiciliária, partimos da definição de que ela é um instrumento de assistência à saúde com o objetivo de prestar atendimento no domic io, orientar, educar, levantar possíveis soluções de saúde, fornecer subsídios educativos para que os indivíduos, a família e a comunidade tenham condições de se tornar independentes.

Achamos oportuno ressaltar aqui a opinião de autores consultados os quais salientam que, para que isto ocorra com efetividade, os conhecimentos sobre a interação e a comunicação assumem papel relevante para os profissionais, no embasamento dos seus contatos com os indivíduos a serem assistidos, considerando que cada pessoa, envolvida numa comunicação, leva consigo seu conhecimento próprio da vida, suas experiências, suas crenças, seus sentimentos.

Em sendo a visita domiciliária direcionada para a educação e para a conscientização dos indivíduos com relação aos aspectos de saúde no seu próprio contexto, esses conceitos deverão ser sempre lembrados, uma vez que o resultado desejado deverá ser a mudança de comportamentos realizada a partir de novas convicções que forem sendo adquiridas pelos educandos, isto é: indivíduos, famílias e comunidade e até os próprios agentes de saúde.

Porém, na época atual em que se dá grande importancia à racionalização e à educação, não seria admissível o uso de medidas de coerção explícitas. A assistência à saúde hoje, teoricamente, pauta-se nos princípios salientados no relatório da conferência de Alma-Ata: eficácia, efetividade e eficiência, dificilmente conseguidos com medidas coercitivas.

Quanto aos dois primeiros, não se pode negar que os conhecimentos da moderna administração os garantam por meio de planejamento e de organização adequados que devem incluir o conhecimento e o provimento das condições imprescindíveis a um projeto assistencial: o diagnóstico da problemática de saúde, a previsão e a provisão dos meios necessários para se fazer face a essa problemática; incluindo-se aí os recursos humanos vistos no seu contexto global - quem deve trabalhar, para fazer o que, porque, quanto, como, quando. Evidentemente está subentendido nesse "como" o preparo adequado.

Também é sabido que o terceiro princípio, o da eficiência, é a mola da racionalização do processo de assistência à saúde, sendo pautado numa operação de lógica da qual um bom exemplo é o seguinte silogismo: $1^{\circ}$ ) a raiva é uma doença inapelavelmente mortal e sem tratamento; $2^{\circ}$ ) a única medida para se evitar a morte de indivíduos contaminados pelo micróbio da raiva é o uso da vacinação anti-rábica, mesmo se for de alto custo; $3^{\circ}$ ) logo, a vacinação desses indivíduos - cães e humanos - é uma medida a ser indiscutivelmente adorada, uma vez que o benefício - a salvação de vidas - justifica qualquer custo.

As necessidades de saúde entre nós são enormes e os recursos para satisfazê-las, no contexto político em que vivemos, são sempre escassos e insuficientes. Essa insuficiência condiciona uma estratégia, "a do estabelecimento de uma gradação" na importancia dos problemas, de tal forma que a ordem de classificação de cada problema seja equivalente à sua colocação prioridade - na escala de importância em termos de riscos para a saúde.

A racionalização das ações de saúde têm, portanto, em vista um planejamento inteligente da assistência.

Sendo a visita domiciliária uma técnica que exige profissional capacitado e treinado adequadamente, com uma grande disponibilidade de tempo na sua execução, demanda uma racionalização 'dos serviços para essa atividade. O fator que pesa grandemente nesta racionalização é o equilíbrio entre o seu custo / benefício, o que torna a visita domiciliária difícil de ser utilizada sistema= ticamente pelos serviços.

Pondera-se que a visita domiciliária, enquanto estratégia de assistência de saúde, poderia ser indicada e justificada para aqueles clientes que mereceriam um monitoramento maior dos serviços de saúde, ficando o seu custo assim justificado. Poder-se-ia através dela, também, proporcionar um suporte maior ao cuidado efetuado nos serviços de saúde, servindo como estratégia de reforços das orientações, como forma de esclarecimento das dúvidas dos clientes, sedimentação de conhecimentos, reflexão e auxílio na resolução dos problemas da família, levantando sugestões de possíveis caminhos dentro da comunidade.

Ao se resgatar o processo histórico da visita domiciliária, o que se pretendeu foi contextualizá-la, no momento histórico em que se desenvolveu, com o fim de contribuir para conhecêla e explicá-la. Os primórdios da visita domiciliária no mundo, num primeiro momento, mostraram que ela teve a finalidade de minimizar a dor sem a preocupação de promover o indivíduo.

Posteriormente, sua ação seria justificada com o discurso de proteção da saúde dos indivíduos e a valorização da qualidade de vida, mas o objetivo maior era o aumento da produção económica interna dos países. A profissionalização da visita domiciliária torna-se imprescindível e uma consequência para a prestação de assistência domiciliária. 
No Brasil o processo foi o mesmo, embora tenha acontecido depois do ocorrido na Europa e Estados Unidos. A ideologia foi importada, os modelos copiados e adaptados à nossa realidade.

A população precisava estar minimamente saudável para poder aumentar a sua capacidade de força de trabalho e responder aos propósitos do governo.

A criação da Fundação SESP é um exemplo disso, pois através dela e com seu apoio na área de saúde foram enviados técnicos americanos para as regiões da Amazônia e do Vale do Rio Doce, com o propósito de respaldar a exploração da borracha e do minério de ferro. A visita domiciliária entre outras ações de saúde, foi utilizada como meio de controle da saúde desta população.

Outro marco importante foi a criação do SESA que tinha como objetivo a prestação de assistência, também utilizando a visita domiciliária.

O seu caráter principal era quanto à qualidade dessa assistência e a qualidade dos profissionais que a executavam. O seu trabalho tinha uma linha norteadora e serviu de marco para todo o país. Foi um exemplo de prestação de cuidado domiciliar, por muito tempo.

Contudo, a política de saúde durante todo o período da história do Brasil pouco contribuiu para que as ações direcionadas de saúde pudessem realmente atender as reais necessidades da população.

Pode-se observar no decorrer da história que, através do sucateamento da saúde, as ações

\section{BIBLIOGRAFIA}

ADAMI, N. P. Aspectos teóricos dos cuidados primários de saude Rev. Esc. Enf. USP, 14(3): 229-235,1980.

ARCHER, S. E.; FLESHMAN, R. Enferrnaria de salud comunitaria. Colômbia, OPSJOMS, 1977.

AUGUSTO, I.; FRANCO, L. H. R. O. Aspectos históricos da assistência de enfermagem domiciliária. Rev. LAES/HAES, 1(5):50-52, 1980.

CASTELLANOS, B. E. P. Estrutura conceitual da enfermagem brasileira. Trabalho apresentado na $2^{\text {a }}$ Sessão da Semana Wanda de Aguiar Horta, 1987, São Paulo [mimeo].

CONFERENCIA INTERNACIONAL SOBRE CUIDADOS PRIMARIOS DE SAUDE, Alma Ata, 1978. Relatório. Brasília, Unicef, 1979.

COSTA, J. Visitação domiciliária - base para o ensino de enfermagem na comunidade. Enf. Nov. Dimen., 3(2): 78-82, 1977. desenvolvidas junto ao individuo, fam^^llia e comunidade foram tornando-se ineficazes, sem efeito e ineficientes e com elas a visita domiciliária.

Podemos concluir que, através da bibliografia especializada, não existe discórdia quanto à utilidade e a importância da visita domiciliária, como instrumento de assistência de saúde desenvolvido pela enfermeira de Saúde Pública. O que se verifica, no entanto, é a necessidade de uma reflexão maior sobre qual a melhor forma de se usar a visita domiciliária como um meio para se promover a saúde.

O assunto é polêmico e os questionarnentos são muitos quanto ao seu enfoque controlador, ao seu alto custo e seu aspecto educativo. No entanto, consideramos de relevância o aprofundamento no estudo do tema, uma vez que não há unanimidade quanto ao seu papel secundário enquanto atividade de promoção de saúde dos indivíduos.

Cabe aqui um questionamento final: seria o fenomeno do desuso da visita domiciliaria propriamente uma opção técnica ou uma decisão pautada na racionalização de recursos?

\section{AGRADECIMENTOS}

À Profa. Dra. Doralice de Souza, pela grande contribuiçao em sua orientação.

À Profa. Dra. Maria de Lourdes Rodrigues, cujas informações como testemunha de fatos significativos foram de grande proveito.

DOMINGUES, F. E. A enfermagem e os novos rumos da saúde comunitária. Rev. Paul. Enf., 2(2): 624. 1982.

GARCIA, J. M. S.; MORENO, M. F. Los problemas familiares y sus repercusiones en el niño. Rev. Med. I.M.S.S., 23(2): 159-166, México, 1985.

HORTA W. A. Da necessidade de se conceituar enfermagem. Enf. Nov. Dimen., 1(1): 5-7, 1975.

MINISTÉRIO DA SAUDE - Secretaria Nacional de Assistência à Saúde. ABC do SUS Doutrinas e princípios. Brasília, 1990.

MIRANDA, C. M. L. Os doce(i)s corpos do hospital: as enfermeiras e o poder institucional na estrutura hospitalar. Rio de Janeiro, 1987 [Tese de Mestrado - Universidade Federal do Rio de Janciro].

NOGUEIRA, M. l. C. Subsidios para a descrição do conteúdo global da ocupação enfermeira de saúde pública. Enf. Nov. Dimen., 1(3):119125, 1975. 
NOGUEIRA, M. I. C. Assistência de enfermagem à família Enf. Nov. Dimen., 3(6):327-346, 1977.

NOGUEIRA, M. J. C.; SERPA DA FONSECA, R. M. G. A visita domiciliária como método de assistência de enfermagem à família. Rev. Esc. Enf. USP, 11(1): 28-50, 1977.

NOGUEIRA, M. J. C. et al. Um modelo de histórico e plano de assistência de enfermagem família. Rev. Esc. Enf; USP, 12(1): 17-60, 1978.

NOGUEIRA, M. I. C. O processo de enfermagem em enfermagem comunitária: uma proposta. Rev. Paul. Enf., 3(1): 15-20, 1983.

NOGUEIRA, M. J. C. Enfoque de risco na assistência de enfermagem comunitária. Rev. Esc. Enf. USP, 18(3): 271-85, 1984.

NOGUEIRA, M. J. C. Pesquisa em enfermagem comunitária. In: Seminário Nacional de Pesquisa em Enfermagem, 4ª , São Paulo, 1985. Anais. Sao Paulo, Associação Brasileira de Enfermagem, 1985. p. 45-59.

ORGANIZACION MUNDIAL DE LA SALUD. El papel de la enfermera em la atencion primaria de salud. Genebra, 1977. (OMS Publicacion Cientifica, 348).
OSHIRO, J. H. Educação para a saúde nas instituições de saúde. Sao Paulo, 1988. [Tese de Mestrado - Pontifícia Universidade Católica de São Paulo].

PADILHA, M. I. C. S. et al. Visita domiciliar: uma alternativa assistencial. Hosp. Adm. e Saúde, 18(1 ): 39-43, 1994.

SILVA, D. T.; NÓBREGA, M. R. S. Desenvolvimento de um programa de porteiras domiciliares. Enf: Atual, 2(10): 13-14, 1980.

VELASQUES, C. L. et al. O enfermeiro no desenvolvimento da comunidade: atuaçao como educador. Rev. Bras. Enf., 39(213): 16-20, 1986.

YOSHIOCA, M. R. et ai. Análise das condições de assistência de saúde do grupo materno-infantil no Brasil. Parte I. Rev. Paul. Hosp., 36(10/12): 173-180, 1988.

YOSHIOCA, M. R. et ai. Analise das condições de assistência de saúde do grupo materno-infantil no Brasil: proposta de ações de enfermagem. Parte II. Rev. Paul. Hosp., 37(1/4): 30-8, 1989.

recebido em: 03/03/95 aprovado em: 10/04/95 